\title{
Disturbed mother-infant interaction in association with congenital heart disease
}

\author{
F V Gardner, N H Freeman, A M S Black, G D Angelini
}

\begin{abstract}
Objective-To investigate whether difficulties are experienced in the interaction between infants with congenital heart disease and their mothers and to identify infants who show compromised emotional development, in order to offer intervention during the early stages of postoperative compensatory growth.

Methods-20 infants and their mothers were compared with 20 non-cardiac mother-infant pairs. Infants were filmed in interaction for 30 minutes two days before and six months after corrective surgery. Fifteen minutes of film were analysed in 180 5-s units. The emotional tone (affect) and the interpersonal engagement were classified as positive or negative by prespecified criteria. The percentages of positive scores were analysed. The mental health of the mothers was also assessed.

Results-Cardiac infants showed less positive affect and engagement than the noncardiac group at both sessions. There was no correlation between of positive affect or engagement and the severity of the condition in either group. Cardiac mothers showed less positive affect and engagement than the comparison group, and were psychologically distressed at both sessions. The engagement scores of the mothers of the cardiac infants were also more variable.
\end{abstract}

Conclusions-Cardiac infants and their mothers have lower levels of positive affect and engagement than non-cardiac mother-infant pairs. Thus some mothers are unable to adapt to their infant. This leads to disordered interaction which is maintained at six months. This information can be used to offer intervention during the early stages of postoperative compensatory growth.

(Heart 1996;76:56-59)

Keywords: congenital heart disease; mother-infant interaction

Considerable progress has been made in the last decade in both the treatment and survival of infants with congenital heart disease. Knowledge of the psychological impact of the disease, however, has not kept pace with these advances. ${ }^{1}$

Infancy is a crucial period for psychological development. Infants are responsive from birth to specifically human qualities. ${ }^{2-4}$ They also develop an early preferential responsiveness to the qualities of the person who consistently cares for them. ${ }^{5-8}$ This has special significance for the care giver, particularly when engaging in face to face interaction. ${ }^{8-13}$ Sensitive and responsive interaction is crucial to the psychological development of the infant. When this does not occur, the infant's functioning is compromised. ${ }^{14} 15$ This is shown by increased levels of distress and by attempts to evade contact with their mothers. ${ }^{1516}$ These effects have been found in premature infants ${ }^{17}$ and in those with postnatally depressed mothers. ${ }^{18} 19$ There is also longitudinal evidence of long term negative effects in both of these high risk groups. ${ }^{20-23}$ There is evidence of an increased incidence of behavioural disorders and attention deficits in school aged children with congenital cardiac disease $^{1}$ but there is currently no published work on mother-infant interaction. It is therefore not known whether infants with congenital heart disease are at risk in terms of compromised emotional development.

\section{Methods}

PATIENT POPULATION

The study included 10 boys and 10 girls, who were admitted electively to the Bristol Royal Infirmary and the Birmingham Children's Hospital for corrective heart surgery. They were born with normal Apgar scores and with birth weights of 3.43 (SD 0.50$) \mathrm{kg}$. Their mean age was $6.3(1.3)$ months. All were free of other congenital abnormalities. Five had transposition of the great arteries, 10 had septal defects, and five had tetralogy of Fallot.

Twenty matching infants were also recruited for comparison: 12 boys, eight girls, mean age $6.2(1.2)$ months; birth weight $3.60(0.54) \mathrm{kg}$; Apgar scores within normal range. One had renal disease, 10 had gastrointestinal disorders, five had pneumonia, and four had multiple infections.

Mothers of the cardiac infants were of similar age to the mothers of the non-cardiac infants: 28 (4) $v 28$ (5) years. All the mothers had stable partners and none had financial hardship (that is, none was receiving income support).

\section{PROCEDURES}

Ethics approval for the study was obtained from the relevant hospital ethics committees. Parents were provided with information and were asked to sign a consent form. Having been admitted and settled in hospital, the mother-infant pairs were visited in the cardiac surgery unit and observed for approximately 
one hour before any formal recording was undertaken to ensure that the interaction recorded on film was representative. The mother-infant pairs were filmed for $30 \mathrm{~min}$ in a room adjacent to the cardiac unit, using a Panasonic video camera with wide angled lens and internal microphone. The infant was made comfortable in a chair that provided the necessary support and permitted movement of all limbs. The mother was asked to play with her infant "as she would normally". It was stressed that filming could be discontinued at any stage if the mother felt it necessary, so if the women felt uncomfortable the session would not be recorded. The comparison group was filmed in the same way and in the same setting. The second filming session was recorded at home 6 months after surgery.

For the first $7 \mathrm{~min}$ of film the mother was asked to play with the infant using two small toys. This acted as a "settling in period" and verified that the infant was alert. The final 8 min provided for a retrospective check on unsuspected difficulties (such as tiredness or discomfort) and was not used in the analysis. The middle $15 \mathrm{~min}$ of film were divided into 180 units of $5 \mathrm{~s}$. The films were then analysed using a standard format (microanalysis ${ }^{24}$ ) which classifies behaviour in terms of affect (for example, smiling) and interpersonal engagement (for example, giving and receiving a toy). The descriptive terms listed in table 1 were used to characterise the behaviours of mother and infant during each $5 \mathrm{~s}$ unit previously classified as positive or negative according to the contribution made to the interaction. The percentages of positive interactions (for example, attention seeking, imitation, gaze following of mother's action) and positive affect (for example, smiling, relaxed, contentment) were calculated for both infant and mother, and the positive scores were the principal measures by which the cardiac and the non-cardiac groups were compared.

Four other independent judges scored three films to ensure satisfactory levels of inter-rater reliability (92\% agreement on affect, and $87 \%$ on engagement).

GENERAL HEALTH QUESTIONNAIRE

Each mother completed the general health questionnaire (GHQ) at both sessions, in

Table 1 Categories used for the analysis to characterise mother and infant affect and engagement

\begin{tabular}{|c|c|}
\hline $\begin{array}{l}\text { Interpersonal affect } \\
\text { (positive } 1,2,3,4 ; \\
\text { negative } 5,6,7,8,9)\end{array}$ & $\begin{array}{l}\text { Interpersonal engagement } \\
\text { (positive } 1,2,3,4,5,6,7,8,9 \text {; } \\
\text { negative } 10,11,12,13,14,15,16 \text { ) }\end{array}$ \\
\hline $\begin{array}{l}1 \text { Affectionate } \\
2 \text { Sympathetic } \\
3 \text { Amused/enjoy } \\
4 \text { Content } \\
5 \text { Afraid } \\
6 \text { Withdrawn } \\
7 \text { Sad } \\
8 \text { Upset } \\
9 \text { Exasperated }\end{array}$ & 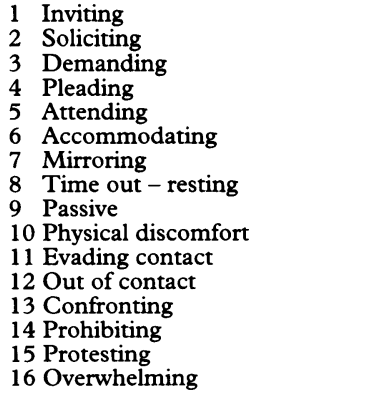 \\
\hline
\end{tabular}

order to assess the possibility of a relation between psychological distress and disturbances in the interaction between mother and infant.

The 30 item version of the GHQ (GHQ 30) was used which is optimal for assessing psychological distress over the previous three weeks. ${ }^{25}$ The GHQ was scored according to the Likert method, which allocates a score of $0,1,2$, or 3 , depending on the severity of the symptoms (a score of 0 represents no distress and 3 indicates a high level). The questions include an investigation of a subject's mood and capacity to sleep and concentrate. A total score of more than 39 is considered to indicate significant psychological distress. ${ }^{25}$

A semistructured interview was also conducted at both sessions, which focused on past and present experiences and concerns for the future; relations with the infant and other relatives were also covered. This served to verify the information provided by the self report questionnaire.

\section{STATISTICAL ANALYSIS}

The results are presented as means and standard deviations. Comparisons of mothers, infants, and mother-infant pairs were analysed using analysis of variance, paired $t$ tests, and Pearson product moment correlations. A P value of 0.05 was considered significant.

\section{Results}

INFANTS

Cardiac infants showed significantly less positive affect and engagement than the comparison group at both filming sessions (table 2). There was no correlation between levels of positive affect or engagement and severity of the condition in either group at the first or second filming session (table 2). There was a highly significant difference in the levels of positive engagement between sessions, but there was no difference in positive affect (table 3).

\section{MOTHERS}

Cardiac mothers also showed less positive affect and engagement than the comparison group at both sessions (table 2). The levels of affect and engagement in the cardiac mothers was more variable than in the non-cardiac mothers. Variability in the cardiac mothers' engagement showed a skew and a suggestion of bimodality (figure). There was no correlation between levels of positive affect or engagement and severity of the medical condition in either group at the first or second filming session.

Cardiac mothers were significantly more distressed than the comparison group, as assessed by the GHQ. Fifteen of the cardiac mothers had a score of over 39 at the first session. None of the mothers reached threshold at the second session (see above). There was a highly significant difference in the levels of positive affect between sessions but there was no difference in positive engagement (table 3). 
Table 2 Mother and infant levels of positive affect and engagement: means and standard deviations

\begin{tabular}{|c|c|c|c|c|}
\hline & \multicolumn{2}{|l|}{ Cardiac } & \multicolumn{2}{|l|}{ Non-cardiac } \\
\hline & 1st Session & 2nd Session & 1st Session & 2nd Session \\
\hline $\begin{array}{l}\text { Infants } \\
\text { Affect } \\
\text { Engagement }\end{array}$ & $\begin{array}{l}45 \cdot 8(16 \cdot 4) \\
49 \cdot 6(14 \cdot 9)\end{array}$ & $\begin{array}{l}57 \cdot 0(13 \cdot 7) \\
60 \cdot 8(12 \cdot 1)\end{array}$ & $\begin{array}{l}73.5(11.3) \quad(P<0.0001) \\
70.3(8.6) \quad(P<0.0001)\end{array}$ & $\begin{array}{l}83.5(6.3)(P<0.05) \\
86.2(8 \cdot 1)(P<0.0001)\end{array}$ \\
\hline $\begin{array}{l}\text { Mothers } \\
\text { Affect } \\
\text { Engagement } \\
\text { GHQ }\end{array}$ & $\begin{array}{l}71 \cdot 6(11 \cdot 4) \\
69.7(20 \cdot 5) \\
43 \cdot 8(17 \cdot 1)\end{array}$ & $\begin{array}{l}78 \cdot 5(8 \cdot 2) \\
75 \cdot 2(17 \cdot 9) \\
24 \cdot 7(8 \cdot 2)\end{array}$ & $\begin{array}{ll}82.4(9.9) & (\mathrm{P}<0.05) \\
83.2(9.0) & (\mathrm{P}<0.05) \\
24.7(8.2) & (\mathrm{P}<0.001)\end{array}$ & $\begin{array}{l}85.0(9.5)(P<0.05) \\
85.6(6.5)(P<0.05) \\
24.7(8.2)(P<0.001)\end{array}$ \\
\hline $\begin{array}{l}\text { Correlations } \\
\text { Mother-infant affect } \\
\text { Mother-infant engagement }\end{array}$ & $\begin{array}{l}0 \cdot 120 \\
0 \cdot 340\end{array}$ & $\begin{array}{l}-0.063 \\
-0.109\end{array}$ & $\begin{array}{l}0.097 \\
0.424\end{array}$ & $\begin{array}{l}0 \cdot 221 \\
0 \cdot 187\end{array}$ \\
\hline
\end{tabular}

Table 3 Mother and infant levels of affect, engagement and $G H Q$ scores: means and standard deviations sessions 1 and 2

\begin{tabular}{|c|c|c|}
\hline & Session 1 & Session 2 \\
\hline \multicolumn{3}{|l|}{ Infants } \\
\hline Affect & $45 \cdot 8(16 \cdot 4)$ & $57.0(13.7)(\mathrm{P}<0.01)$ \\
\hline Engagement & $49.6(14.9)$ & $60.8(12.1)(\mathrm{P}<0.0001)$ \\
\hline \multicolumn{3}{|l|}{ Mothers } \\
\hline Affect & $71 \cdot 6(11 \cdot 4)$ & $78.5(8.2) \quad(P<0.0001)$ \\
\hline Engagement & $69.7(20 \cdot 5)$ & $75.2(17.9)(\mathrm{NS})$ \\
\hline $\mathrm{GHQ}$ & $43 \cdot 8(17 \cdot 1)$ & $24.7(8.2) \quad(\mathrm{P}<0.001)$ \\
\hline
\end{tabular}

\section{MOTHER-INFANT PAIRS}

Correlations between mother and infant for affect score and engagement score were nonsignificant for both groups at either session (table 2). There was also no correlation between maternal affect and engagement and infant affect and engagement at either session. The correlation between the GHQ and affect scores was significant for the non-cardiac mothers but not for the mothers of the cardiac infants at both sessions. Correlations between GHQ and engagement scores for the mothers were significant for both groups (table 2).

\section{Discussion}

Our study shows that difficulties are experienced in the interaction between a significant

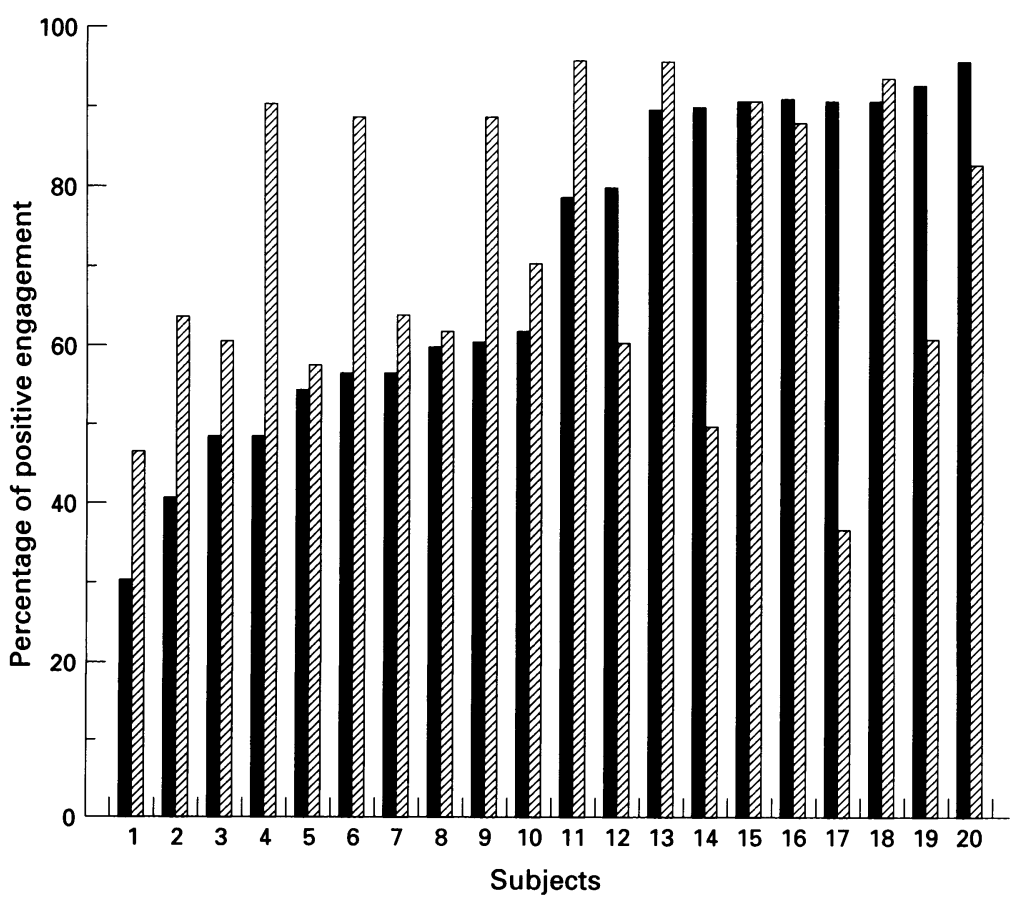

Positive engagement of mothers and their infants in the cardiac group during sessions 1 and 2. number of cardiac infants and their mothers. More specifically, the cardiac infants were consistently different from non-cardiac infants at the level of interpersonal engagement.

Normal infants are innately motivated to engage in sustained periods of cooperative interaction with the person who consistently cares for them, and this is crucial to psychological development. ${ }^{815}$ Study of the video recordings shows that cardiac infants have difficulty in sustaining engagement with their mothers, causing interaction to break down frequently in some pairs. The number of interruptions in interaction are indicated by low levels of engagement in the mother. It is therefore these mother-infant pairs that we aim to identify in order to offer therapeutic intervention during the early stages of postoperative compensatory growth.

A significant number of mothers responded to the lack of engagement either by overstimulating their infants in an attempt to regain their attention or by withdrawing from the interaction and appearing to be distressed by their infants' behaviour. This often caused the infant to withdraw further. Some mothers respond to the interruption by waiting for their infant to resume engagement. If the mother is able to allow the infant to pause, the infant will return in time to the interaction, and a normal pattern can be resumed until further interruptions occur. It was interesting that no correlation was found between the mothers' and the children's affect or engagement scores; thus the mothers whose infants' engagement was low were in many cases able to accommodate to the interruptions in interaction and managed to maintain a positive emotional presence for the child. On the other hand some mothers were not able to accommodate any interruption in interaction at all. These modes of interaction are represented in the levels of positive engagement. It can be seen that a percentage of cardiac mothers maintain high levels of positive engagement by accommodating to the interruptions in the interaction, but that a significant number of the mothers are not able to make such accommodations and the levels of positive engagement are correspondingly lower. This is consistent with the bimodality seen in the levels of positive engagement in the figure with the helpful adaptations represented in the higher levels of engagement ( $>80 \%)$.

Difficulties in interaction stem from either the infant or the mother. Possible risk factors attributed to infants are low weight at birth, ${ }^{17}$ postnatal growth compromised by cardio- 
vascular disturbance, ${ }^{26}$ particularly in the presence of cyanosis, ${ }^{27}$ and where social interactions have been hampered by problems in breathing, eating. and stamina. ${ }^{28}{ }^{29}$ Low levels of engagement in the interaction of infants with congenital heart disease may be due to such factors.

Difficulties arising from the principal caretaker (usually the mother) which can result in disordered emotional and cognitive responses to the child may be due to significant mental health problems ${ }^{819}$ or having to cope with an infant with a disability or mental handicap. ${ }^{29}$ Mothers of cardiac infants report high levels of frustration and distress at feeling unable to nourish and calm their infants adequately ${ }^{24}$ and this may affect the reactions of both mother and infant at a time when normal bonding is required. ${ }^{30}$ Distress in these parents may be accentuated when coping with the feelings of having an infant with congenital cardiac disease and coping with particular problems of loss of a normal child once the disease is diagnosed. It was therefore particularly important to screen for mental health symptoms in our subject group. Indeed three quarters of the mothers of the cardiac infants were significantly psychologically distressed. The mothers may well have been particularly distressed at the time of the preoperative session, but preoperative anxiety does not affect the infant and it is the mother's accommodation to infant behaviour that is the crucial aspect of our findings. This accommodation (represented in high levels of positive engagement) occurred in many of the mothers who were significantly psychologically distressed. This is shown by the fact that there was no correlation between GHQ scores and levels of engagement and no significant difference was found between preoperative and postoperative maternal affect or engagement.

There is no published evidence on the effects of congenital heart disease on motherinfant interaction, so it very important for future research to investigate specifically how mothers accommodate to the difficulties that infants have in sustaining engagement in interaction. It is also important to establish whether these difficulties are maintained. Although there is a significant improvement in levels of positive engagement over time, the level remains low compared to non-cardiac infants. If low levels of engagement persist throughout early childhood, there are implications for compromised emotional development. The potential for reducing these difficulties in interaction by providing psychological intervention aimed at accelerating and increasing improvements in engagement from around the time of diagnosis needs to be investigated.

\section{CONCLUSION}

The period of infancy is crucial to the development of healthy psychological functioning, and the effects of cardiac disease on this may have been underestimated previously. The presence of congenital heart disease affects motherinfant interaction in a significant number of pairs. Cardiac infants have low levels of engagement and some mothers appear to be unable to adapt to this, leading to disordered interaction.

This work was supported by the British Heart Foundation and the Garfield Weston Trust.

1 Garson SL, Baer P. Psychological aspects of heart disease in childhood. In: Garson A, Bricker JJ, McNamara DG, eds. Science and practice in pediatric cardiology. Philadelphia: Lea and Febiger, 1990;152:2519-26.

2 Field TM. Neonatal perception of people: motivational and individual differences. In: Field TM, Fox R, eds. Social perception in infants. New Jersey: Ablex and Norwood, 1985:34-47.

3 Mehler J, Fox R. Neonate cognition: beyond the blooming buzzing confusion. Hillsdale: Earlbaum, 1985:67-75.

4 Goren CG, Sarty M, Wu PYK. Visual following and pattern discrimination of face-like stimuli by newborn infants. discrimination of face-like
Pediatrics 1975;56:544-9.

5 De Casper AJ, Fifer WP. Of human bonding: newborns prefer their mother's voice. Science 1980;208:1174-6.

prefer their mother's voice. Science 1980;208:1174-6. infancy. Merrill-Palmer Q 1970;16:7-51.

7 Widmer-Robert-Tissot C. Les modes de communication du bébé: postures, mouvements et vocalisés. In: Delachoux et Nestlé, eds. Actualités pedagogiques et psychologiques. Paris: Neuchatel, 1981:34-51.

8 Trevarthen CB. Instincts for human understanding and for cultural co-operation: their development in infancy. In von Cranach M, Foppa K, Fepenies W, Plooge D, eds. Human ethology. London: Cambridge University Press, 1979:148-70

9 Trevarthen CB, Murray L, Hubley PA. Psychology of infants. In: Davis JA, Dobbing J, eds. Scientific foundations of paediatrics, 2nd ed. London: Heinemann, 1981: 200-64.

10 Trevarthen CB. Communication and cooperation in early infancy: a description of primary intersubjectivity. In: Bullowa M, ed Before speech. London: Cambridge University Press, 1979:267-315.

11 Trevarthen CB, Hubley P. Secondary intersubjectivity: confidence, confiding and acts of meaning in the first year. In: Lock A, ed. Action: gesture and symbol: the emergence of lanLock A, ed. Action: gesture and symbol: the emergence

guage. London: Academic Press, 1978:183-229.
12 Bullowa M. Before speech: the beginning of interpersonal communication. London: Cambridge University Press, 1979:
mallowa munica.

13 Trevarthen CB, Logotheti K. First symbols and the nature of human knowledge. In: Montangero J, Tryphon A Dionnet S, eds. Symbolism and knowledge cahier. Geneva: Jean Piaget Archives Foundation, 1987: 89-101.

14 Stern DN. The first relationship: infant and mother. Cambridge: Harvard University Press, 1977:7-35.

15 Stern D. The interpersonal world of the human infant: a view from psychoanalysis and developmental psychology. New York: Basic Books, 1985:13-68.

16 Sylvester-Bradley B. Negativity in early infant adult exchanges and its developmental significance. In: Robinson $\mathrm{P}$, ed. Communication in development. London: Academic Press, 1981:31-56.

17 Holmes D, Reich JN, Pasternak JF. The development of infants borm at risk. London, NJ: Lawrence Erlbaun Associates, 1984:147-9.

18 Murray L. The sensitivities and expressive capacities of young infants in communication with their mothers. Edinburgh infants in communication with their mothers.

19 Murray L. Effects of postnatal depression on infants develIn: Kumar R, Brockington I, eds. Motherhood and mental In: Kumar R, Brockington I, eds. Motherhood and mental

illness. II. London: John Wright and Sons, 1988:68-89.
20 Wrate RM, Rooney AC, Thomas PF, Cox P. Postnatal Wrate RM, Rooney AC, Thomas PF, Cox P. Postnatal
depression and child development: a three year follow-up

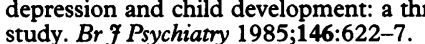

21 Coghill SR, Caplan HL, Alexandra H, Robson KM, Kuma R. Impact of maternal postnatal depression on cognitive R. Impact of maternal postnatal depression on cognitive
development of young children. $B M \Im$
$1986 ; 292: 1165-7$.

22 Mills M, Puckering C, Pound A, Cox A. What is it about depressed mothers that influences their children's functioning? In: Stevenson JE, ed. Recent research in developmental psychopathology. Oxford: Pergamon Press, 1985: 76-92.

23 Klein M, Stern L. Low birthweight and the battered child syndrome. Am $f$ Dis Child 1985;122:15-18.

24 Trevarthen CB, Marwick H. Co-operative understanding in infants. Project report to the Spencer Foundation Edinburgh: Department of Psychology, University of Edinburgh, 1985 .

25 Goldberg DP. The detection of psychiatric illness by questionnaire. Oxford: Oxford University Press, 1972

26 Loeffel M. Developmental considerations of infants and children with congenital heart disease. Heart Lung 1983; 14:214-7.

27 Silbert A, Wolff PH, Mayer B, Rosenthal A, Nadas A. Cyanotic heart disease and psychological development. Pediatrics 1969;43:192-200.

28 Garson A, Benson S, Ivler L, Patton C. Parental reactions to children with congenital heart disease. Child Psychiatry Hum Dev 1978;9:86-94.

29 Pollak M.Textbook of developmental paediatrics. Edinburgh: Churchill Livingstone, 1993:34-67.

30 Klaus MH, Kennel JH. Maternal-infant bonding. St Louis: The CV Mosby Co, 1976:28-53. 